\title{
Early development of the red mouthed goby, Gobius cruentatus (Pisces: Gobiidae)
}

\author{
Fátima Gil*, Rita Borges ${ }^{\dagger}$, Cláudia Faria ${ }^{\dagger \ddagger}$ and Emanuel J. Gonçalves ${ }^{\dagger}$ \\ *Aquário Vasco da Gama, Rua Direita, Dafundo, P-1495 Lisboa, Portugal. \\ ${ }^{\dagger}$ Unidade de Investigação em Eco-Etologia, Instituto Superior de Psicologia Aplicada, \\ Rua Jardim do Tabaco 34, P-1149-041 Lisboa, Portugal. \\ ${ }^{\ddagger}$ Corresponding author, e-mail: cfaria@ispa.pt
}

\begin{abstract}
The full developmental embryonic sequence of Gobius cruentatus is described for the first time. Embryonic development lasted 13 days $\left(14.0-15.0^{\circ} \mathrm{G}\right)$. The newly hatched larvae (3.3 $\mathrm{mm}$ total length) presented pigmented eyes, the yolk is fully absorbed, and the mouth and anus were opened allowing the onset of exogenous feeding almost after hatching.
\end{abstract}

\section{INTRODUCTION}

Gobius cruentatus Gmelin (1789) is an eastern Atlantic goby, occurring from south-west Ireland to Senegal and in the Mediterranean (Miller, 1986). It is found inshore on rocky habitats, sand and sea grass meadows (Wilkins \& Myers, 1992). Although abundant throughout its distributional range, the reproductive biology of this species is virtually unknown. The existing information is concerned mainly with distributional patterns and the use of space (e.g. Miller, 1986, 1990; Minchin, 1987; Wheeler, 1992; Wilkins \& Myers, 1992, 1993, 1995).

\section{MATERIALS AND METHODS}

Eggs and larvae were obtained from a pair of captive fish maintained since May 1998 at a public aquarium (Aquário Vasco da Gama, Lisbon). The gobies were fed daily with fish and shrimp. The tank was illuminated with fluorescent light (60W) from 0900 to 1900. The bottom of the tank was covered with a layer of sand and several large flat stones. Eggs were removed from the spawning stone daily by aspiration with a tube and were observed under a Nikon stereomicroscope, photographed by a Nikon Fx-35DX camera and preserved in buffered $5 \%$ formalin.

\section{RESULTS}

The complete sequence of embryonic development (temperature: $14-15^{\circ} \mathrm{C}$ ) was based on a spawning that occurred on 8 December 1998. The breeding male presented a dark coloration with bright red lips. Parental care included fanning and rubbing the eggs with the dorsal fin or the posterior end of the body as described for other species of the genus Gobius (see e.g. Gil et al., 1997; Faria et al., 1998).

The eggs were transparent and fusiform (length= $2.04 \mathrm{~mm}$, range $1.90-2.10 \mathrm{~mm}, \mathrm{SD}=0.08$; width $=0.56 \mathrm{~mm}$, range $0.50-0.60 \mathrm{~mm}, \mathrm{SD}=0.05 ; \mathrm{N}=50$ ) and were attached to the underneath of a horizontal rock by filaments. They were distributed in a single layer within a total area of
$121 \mathrm{~cm}^{2}$ with a density of $176 \mathrm{eggs}^{-2}$. In Figure 1 eggs in different developmental stages and the newly hatched larva are presented. The main ontogenetic events of embryonic development are shown in Figure 2.

Hatching occurred 13 days after fertilization and the egg capsule was disrupted by the lower jaw of the larvae, where hatching glands were visible. The head was the first to emerge after rapid movements of the body. Newly hatched larvae measured $3.30 \mathrm{~mm}$ total length (range $3.24-3.34 \mathrm{~mm}$; $\mathrm{SD}=0.03 ; \mathrm{N}=7$ ). The mouth and anus were open, with formed lips and differentiated jaws. The yolk was fully absorbed. The liver was developed, the eyes were fully pigmented and the gas bladder was filled. The pectoral fins were differentiated and the inner ear already presented the sagittae and lapilli otoliths. The opercules were open and the branchial arches were differentiated.

The larvae presented seven to nine pre-anal melanophores ventrally and one above the anus (Figure 1). There was a continuous row of post-anal melanophores with several large and ramified in the middle of this row. Dorsally, there was a melanophore between the brain and the trunk, and a row of ramified melanophores in the direction of the ventral patch. Internally, the dorsal membrane of the gas bladder was fully pigmented and there were one or two ramified melanophores above the gut. There were also yellow pigments along the entire body, being more concentrated in the regions that contained melanophores.

\section{DISGUSSION}

The sequence of embryonic development described for Gobius cruentatus largely agrees with the known descriptions for other species of the genus Gobius (e.g. Gobius cobitis Pallas, 1811 (Gil et al., 1997); Gobius niger Linnaeus, 1758 (Ballard, 1969); Gobius paganellus Linnaeus, 1758 (unpublished data)). However the incubation periods observed varies between species: $G$. niger also hatch 13 days after spawning, but at a lower temperature $-13^{\circ} \mathrm{C}$ (Ballard, 1969); G. paganellus hatch 11 days after spawning at 15.5$16.5^{\circ} \mathrm{C}$ (unpublished data); G. cobitis present the longer 
A

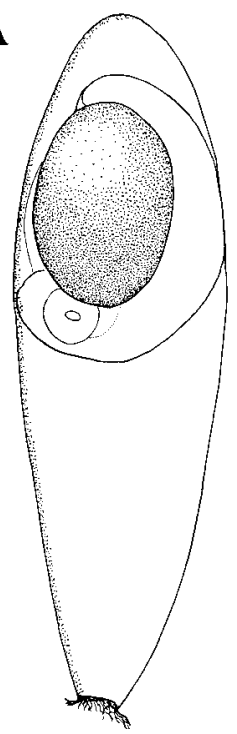

B

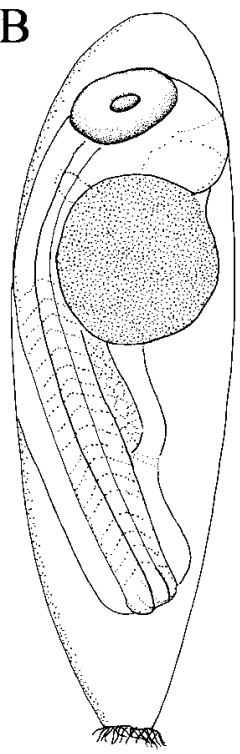

$\mathrm{C}$

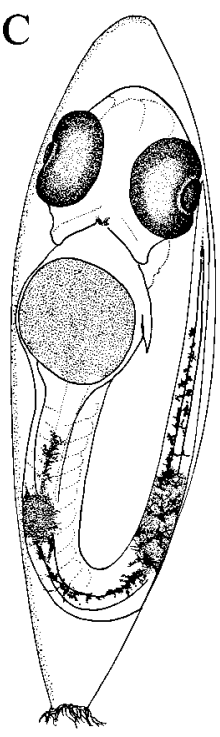

D

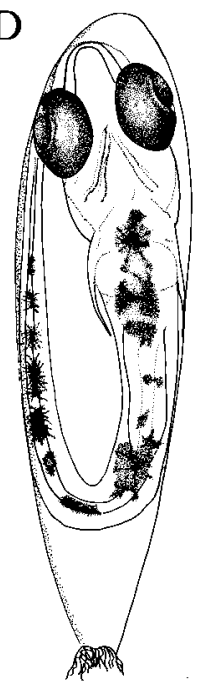

E

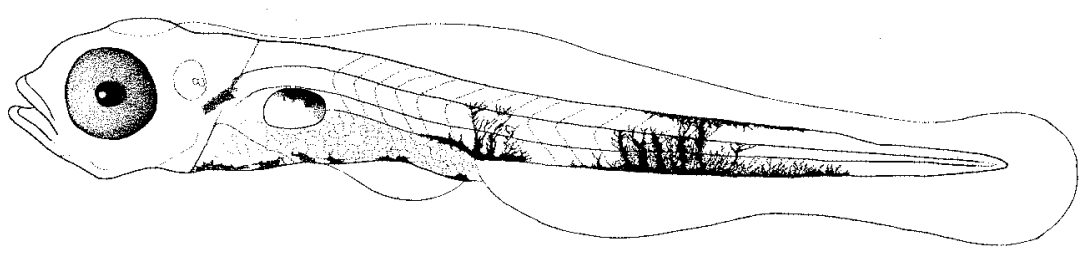

Figure 1. Eggs collected at different developmental stages: (A) day 1; (B) day 4; (C) day 8; (D) day 10; (E) newly hatched larva (3.3 mm total length).

incubation period, $22-24$ days at $12-16^{\circ} \mathrm{C}$ (Gil et al., 1997). These differences are probably related to the size of the newly hatched larvae: $2.5 \mathrm{~mm}$ in G. niger (Ballard, 1969), $3.3 \mathrm{~mm}$ in G. cruentatus, $3.5 \mathrm{~mm}$ in G. paganellus (unpublished data), and $5.5 \mathrm{~mm}$ in G. cobitis (Gil et al., 1997). Additionally, the shorter developmental time described for $G$. paganellus is probably related to the higher incubation temperature, since the decrease of developmental time with higher temperatures is known for many fish species (Blaxter, 1969). This effect could also explain the similar incubation periods observed for G. cruentatus and $G$. niger in spite of the differences in size of the newly hatched larvae. These two factors, size at hatching and incubation temperature, should be clearly differentiated when comparing the early ontogeny of related species.

The area and density of the egg batches are related to species size, since smaller fish tend to have smaller and denser batches (Miller, 1984; Thresher, 1984). This situation was described by Faria \& Almada (1995) for $G$. paganellus and $G$. cobitis, with the smaller $G$. paganellus 


\section{Days}

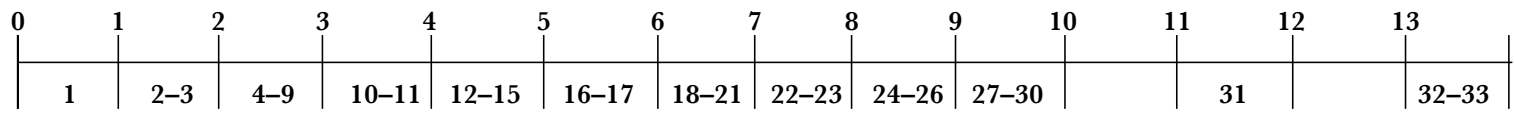

Ontogenetic events of embryonic development

Figure 2. Ontogenetic events of embryonic development of Gobius cruentatus in order of first appearance: (1) embryo recognizable; (2) cephalic and caudal dilatation; (3) embryo reaches the margin of the yolk; (4) eye lens; (5) brain; (6) notochord differentiation; (7) tail bud free of the yolk; (8) myomeres; (9) gut differentiation; (10) brain lobes; (11) embryo movements; (12) auditory vesicles; (13) median fin fold; (14) embryo longer than egg major axis; (15) heart beating; (16) notochord; (17) mouth differentiation; (18) anus visible but closed; (19) pigmented eyes; (20) otoliths; (21) pectoral fin buds; (22) gas bladder; (23) mouth visible but closed; (24) anus opened; (25) hatching glands; (26) opercules visible but closed; (27) mouth opened; (28) liver differentiation; (29) opercules opened; (30) mandibles differentiation; (31) gut movements; (32) eye movements; (33) hatching.

presenting smaller eggs in a higher density. Gobius cruentatus, which is smaller than $G$. cobitis but larger than $G$. paganellus presented intermediate egg densities $(85$ eggs cm ${ }^{-2}$ for $G$. cobitis, $176 \mathrm{eggs} \mathrm{cm}^{-2}$ for $G$. cruentatus and $208 \mathrm{eggs} \mathrm{cm}^{-2}$ for G. paganellus).

Like other coastal species with demersal eggs, the newly hatched larvae of $G$. cruentatus showed the typical pattern of development of marine fish with male parental care (Thresher, 1984). The eyes and pectoral fins were fully developed at hatching with the larvae immediately swimming in an active way. The mouth and anus were opened, allowing the onset of exogenous feeding almost after hatching.

This study was supported by Fundação para a Ciência e Tecnologia (FCT) as part of the projects PRAXIS XXI/3/3.2/ EMG/1957/95 and the Pluriannual Programme (UI\&D 331/94). C.F. was also supported by a grant from FCT (PRAXIS XXI/ $\mathrm{BD} / 5666 / 95)$. We would like to thank the technicians of Aquário Vasco da Gama for the help in the maintenance of tanks and to Maria Dornelas for the illustrations.

\section{REFERENCES}

Ballard, W.W., 1969. Normal embryonic stages of Gobius niger jozo. Pubblicazioni della Stazioni Zoologica di Napoli, 37, 1-17.

Blaxter, J.H.S., 1969. Development: eggs and larvae. In Fish physiology, vol. III: reproduction and growth. Bioluminiscence, pigments, and poisons (ed. W.S. Hoar and D.J. Randall), pp. 178-252. New York: Academic Press.

Faria, C. \& Almada, V.C., 1995. Some aspects of the breeding ecology of Gobius cobitis Pallas and Gobius paganellus L. in the west coast of Portugal. Arquivos do Museu Bocage-Nova Série, II, $463-471$.
Faria, C., Almada, V.C., Gonçalves, E.J., Gil, M.F., Baptista, C. \& Carreiro, H., 1998. Notes on the social behaviour of Gobius cobitis (Pisces, Gobiidae). Acta Ethologica, 1, 49-56.

Gil, M.F., Gonçalves, E.J., Faria, C., Almada, V.C., Baptista, C. \& Carreiro, H., 1997. Embryonic and larval development of the giant goby Gobius cobitis (Pisces: Gobiidae). Fournal of Natural History, 31, 799-804.

Miller, P.J., 1984. The tokology of gobioid fishes. In Fish reproduction: strategies and tactics (ed. G.W. Potts and R.J. Wootton), pp. 119-153. London: Academic Press.

Miller, P.J., 1986. Gobiidae. In Fishes of the north-eastern Atlantic and the Mediterranean (ed. P.J.P. Whitehead et al.), pp. 10191085. Paris: UNESCO.

Miller, P.J., 1990. The endurance of endemism: the Mediterranean freshwater gobies and their prospects for survival. Fournal of Fish Biology, 37, 145-156.

Minchin, D., 1987. Fishes of the Lough Hyne marine reserve. Fournal of Fish Biology, 31, 343-352.

Thresher, R.E., 1984. Reproduction in reef fishes. Neptune City, New Jersey: T.F.H. Publications.

Wheeler, A., 1992. A list of the common and scientific names of fishes of the British Isles. Fournal of Fish Biology, 41, 1-37.

Wilkins, H.K.A. \& Myers, A.A., 1992. Microhabitat utilisation by an assemblage of temperate Gobiidae (Pisces: Teleostei). Marine Ecology Progress Series, 90, 103-112.

Wilkins, H.K.A. \& Myers, A.A., 1993. Shelter utilization by Gobius cruentatus and Thorogobius ephippiatus (Teleostei: Gobiidae). Fournal of Fish Biology, 43, 763-773.

Wilkins, H.K.A. \& Myers, A.A., 1995. Use of space by Gobius cruentatus and Thorogobius ephippiatus (Teleostei: Gobiidae) in south-west Ireland. Marine Biology, 124, 27-34.

Submitted 21 June 2001. Accepted 1 December 2001. 